\title{
Assessment of forest net primary production through the elaboration of multisource ground and remote sensing data
}

\author{
Fabio Maselli, ${ }^{* a}$ Marta Chiesi, ${ }^{a}$ Anna Barbati ${ }^{b}$ and Piermaria Corona ${ }^{b}$ \\ Received 23rd November 2009, Accepted 1st February 2010 \\ First published as an Advance Article on the web 11th March 2010 \\ DOI: 10.1039/b924629k
}

This paper builds on previous work by our research group which demonstrated the applicability of a parametric model, Modified C-Fix, for the monitoring of Mediterranean forests. Specifically, the model is capable of combining ground and remote sensing data to estimate forest gross primary production (GPP) on various spatial and temporal scales. Modified C-Fix is currently applied to all Italian forest areas using a previously produced data set of meteorological data and NDVI imagery descriptive of a ten-year period (1999-2008). The obtained GPP estimates are further elaborated to derive forest net primary production (NPP) averages for 20 Italian Regions. Such estimates, converted into current annual increment of standing volume (CAI) through the use of specific coefficients, are compared to the data of a recent national forest inventory (INFC). The results obtained indicate that the modelling approach tends to overestimate the ground CAI values for all forest types. The correction of a drawback in the current model implementation leads to reduce this overestimation to about $9 \%$ of the INFC increments. The possible origins of this overestimation are investigated by examining the results of previous studies and of older forest inventories. The implications of using different NPP estimation methods are finally discussed in view of assessing the forest carbon budget on a national basis.

\section{Introduction}

Forest ecosystems cover about one third of the Earth's ice-free land surface $^{1}$ and represent both a fundamental natural and economic resource and a significant part of the global carbon stock. ${ }^{2}$ The assessment of forest ecosystem production is therefore a central issue in applied ecology and is becoming increasingly important for evaluating the role of forests as possible carbon sink. ${ }^{3}$

Traditionally, information on forest production is collected through user-driven national forest inventories. ${ }^{4}$ In Italy, a national forest inventory (INFC) has been recently completed. ${ }^{5,6}$ One of the main objectives of this inventory is to provide an updated national estimate of forest carbon sink (i.e.,

${ }^{a} I B I M E T-C N R$, Via Madonna del Piano 10, 50019 Sesto Fiorentino, FI, Italy.E-mail: maselli@ibimet.cnr.it; Fax: +39055 444083; Tel: +39055 5226024

${ }^{b}$ DISAFRI, University of Tuscia, Via San Camillo de Lellis, 01100 Viterbo, Italy; Fax: +390761 357389; Tel: +390761357425 carbon net primary productivity, C-NPP), which can be derived from wood volume increment statistics through the use of biomass expansion factors (BEF) ${ }^{7,8}$ Such statistics are presently published at regional level, together with other information on main forest features (type, basal area, volume, etc.). The C-NPP estimates derived from INFC, however, are only partially in agreement with those from other data sources (e.g. ref. 9 and 10). This indicates the existence of a challenging framework, where uncertainties are rather high.

A procedure which has been recently developed by our research group provides an alternative method to obtain spatial NPP estimates for the main Italian forest categories. ${ }^{10,11}$ The procedure is based on the use of a parametric model, C-Fix, which is driven by conventional and remote sensing data. The model was originally applied in temperate forest ecosystems by Veroustrate et al. ${ }^{12,13}$ and has been adapted to Mediterranean areas by Maselli et al. ${ }^{14}$ The last investigation demonstrates that Modified C-Fix is an efficient predictor of monthly and annual

\section{Environmental impact}

Net primary production (NPP), which corresponds to the amount of biomass accumulated in ecosystems, is the essential parameter which characterizes forests as possible carbon sinks. While recent studies have shown that remotely sensed and ground data can be efficiently combined to predict forest photosynthesis, the conversion of this into NPP is still a complex issue, which requires the consideration of the effects of the disturbances occurred. This issue is currently addressed by using two models, C-Fix and BIOMEBGC, whose outputs are elaborated to assess the NPP of Italian forests. The comparison of the obtained NPP estimates with volume increments from a recent National Forest Inventory confirms the critical nature of this subject area and provides useful indications for future research. 
gross primary production (GPP) of Italian forests at a spatial scale of about $1 \mathrm{~km}^{2}$.

The conversion of the GPP into NPP estimates is, however, a non-trivial issue. The two variables, in fact, are only partially inter-related when forest resources are strongly influenced by management practices or other disturbing factors (wildfires, pests and diseases, etc.). As noted by Maselli et al. ${ }^{15}$ forest GPP is an expression of total ecosystem productivity, which includes the contribution of both trees and understorey vegetation (brushes and grasses). The latter component can even be prevalent when tree density is low due to the effect of heavy disturbances, which is relatively frequent in Italy as well as in most other European countries. In contrast, the forest NPP which can be derived from tree increments is completely related to the accumulation of woody biomass, which is obviously limited in the case of low tree density. This can determine a substantial uncoupling between forest GPP and NPP, which can be further complicated by the effects of variable tree aging and stand development phases. ${ }^{16,17}$ These factors, which are also influenced by the mentioned disturbances, affect the respiration and allocation patterns of forest ecosystems and alter the relationship between GPP and NPP. 18,19,20,21

Several recent papers ${ }^{10,22,23}$ have recognized that the modelling of forest NPP over large European areas is an open field of investigation which requires the application of sophisticated modelling strategies. The approach proposed by Maselli et al. ${ }^{15}$ introduces the concept of ecosystem distance from climax (ecosystem equilibrium condition, sensu Odum 1953) ${ }^{24}$ which is aimed at describing the actual status of forests consequent on the effects of disturbance factors. Climax conditions are simulated by the use of a model of ecosystem processes (BIOME-BGC), and are then converted into the conditions of real ecosystems through the use of a proxy variable given by the ratio of real over potential tree volumes. The approach is generally applicable on a regional scale, with implications and limitations which are fully discussed in the same paper.

The current investigation aims at testing a simplified version of this approach to convert forest GPP predicted by Modified C-Fix into NPP. The modelling approach is applied over the Italian territory at the same resolution used in previous investigations $\left(1 \mathrm{~km}^{2}\right)$, and the outputs are aggregated over all Italian Regions for comparison with INFC data.

The paper is organized as follows. The main features of Italian forests are first described together with those of the ground and remote sensing data utilized. The modelling approach is then introduced together with the steps used for its application on the national territory and validation against INFC increment data. Next, the results are described and discussed, with particular reference to examining the main sources of uncertainty in the evaluation of NPP. The paper is concluded by a section which highlights the potential contribution of the approach for the assessment of forest carbon budget on a national scale.

\section{Study area and data}

\section{Main features of Italian forests}

Italy is geographically situated between $36^{\circ}$ and $47^{\circ} 30^{\prime}$ North latitude and between $5^{\circ} 30^{\prime}$ and $18^{\circ} 30^{\prime}$ East longitude. Its

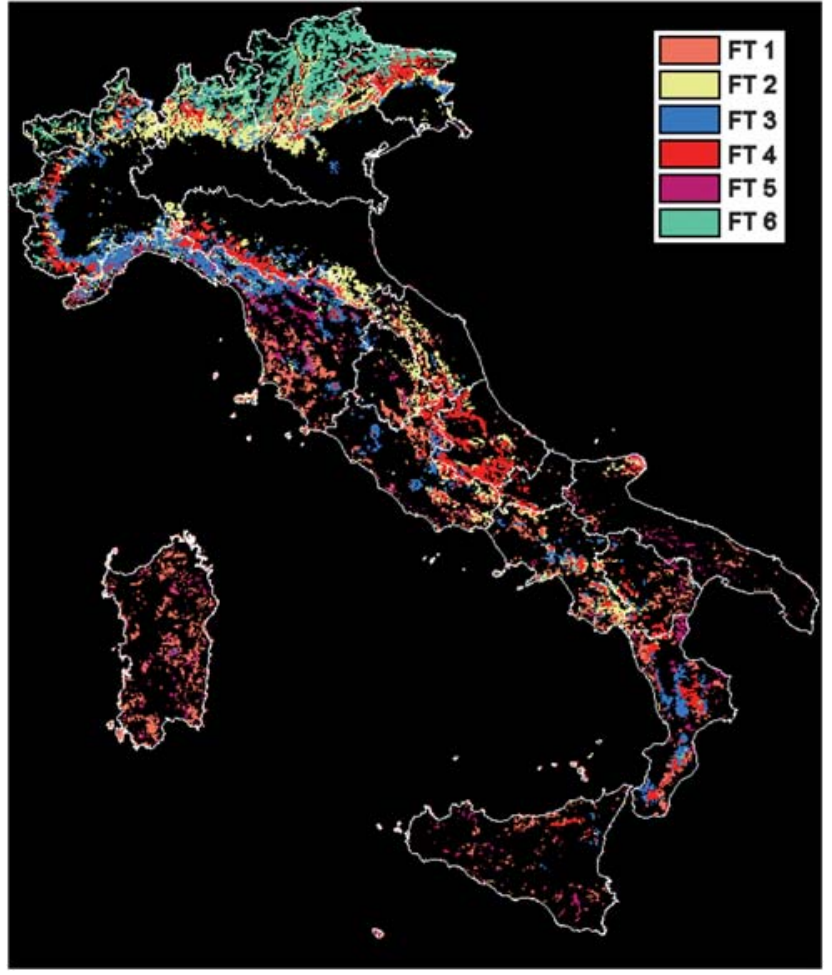

Fig. 1 Spatial distribution of the six forest types examined in Italy, with superimposed administrative boundaries of the 20 Italian Regions.

orography is complex due to the presence of two main mountain chains, the Alps in the north and the Appennines in the centresouth. Italian climate is also very variable following the latitudinal and altitudinal gradients and the distance from the sea: in general, it ranges from Mediterranean warm to temperate cool. The country is administratively divided into 20 Regions (Fig. 1).

According to the CORINE Land Cover 2000 map, ${ }^{25}$ forest land (including bushland) covers nearly $9.2 \mathrm{Mha}$ in Italy. INFC (see www.infc.it), whose data are based on the FAO forest definition, reports a total extent of forest areas equal to $87600 \mathrm{~km}^{2}$. $32 \%$ of the forest formations are included in the Alpine biogeographical region, $16 \%$ in the Continental region and $52 \%$ in the Mediterranean region (sensu Habitat Directive of the European Commission 43/92). According to INFC, the most widespread forest formations are dominated by various oak species (Quercus spp.), a fourth of which is characterized by the prevalence of evergreen oaks, and beech (Fagus sylvatica). Among conifers, the most abundant forest formations are dominated by Norway spruce (Picea abies), followed by mountain pines (Pinus sylvestris, $P$. nigra) and Mediterranean pines (P. halepensis, $P$. pinaster, $P$. pinea).

\section{Data used}

A Digital Elevation Model (DEM) of Italy with a pixel size of 1 $\mathrm{km}^{2}$ is currently used. This DEM is projected in the UTM32North reference system, which is taken as a standard for the processing of all other information layers. Monthly meteorological data are derived from the national network of weather stations managed by UCEA (http: www.ucea.it) from 1999 to 
2008. In particular, monthly average minimum and maximum temperatures and total precipitation are collected from about 90 stations spread all over the national territory. Daily data of the same period are available only for Tuscany Region (Central Italy).

A forest map is derived from the CORINE Land Cover 2000 map of Italy.$^{25}$ The original CORINE dataset of Europe classifies forests at $1: 100000$ scale (minimum mapping size of $25 \mathrm{ha}$ ) in three general classes: broadleaf, coniferous and mixed. ${ }^{26}$ The available forest map instead classifies forests and other wooded land in 26 types on the basis of the dominant species, maintaining the geometric and thematic congruency with the original CORINE dataset. The forest map of Italy was produced by manual photointerpretation of Landsat imagery supported by several ancillary information. ${ }^{25}$ In a previous work ${ }^{11}$ the original vector dataset has been rasterized at the available DEM resolution $\left(1 \mathrm{~km}^{2}\right)$ grouping the original classes into 12 main forest types (FTs). Among these forest types, the six which are most widespread and representative over the Italian territory are selected in conformity with work already done by Chiesi $e t$ al..$^{27}$ for Tuscany (Central Italy). The main features of these six forest types are summarised in Table 1, whilst their spatial distribution is shown in Fig. 1.

Reference forest data are derived from the standing volume and the current annual increments of standing volume (CAI) measured by INFC. ${ }^{5,6}$ This inventory comprised a three-phase sampling: ${ }^{28}$ the first two phases were aimed at estimating the forest area and its distribution into different classes according to qualitative attributes (e.g. property, management issues, vegetation structure and conditions, site features, etc.). The third phase was aimed at collecting quantitative measurements of tree and stand attributes by means of ground surveys carried out on about 7000 plots. During this last phase, several forest variables (tree diameters, tree heights, stem diameter increments, etc.) were collected on a plot basis. Statistics from these measurements are provided in an aggregated form for all Italian Regions (see www.infc.it).

Data from older national or regional forest inventories are also available, i.e. the first Italian Forest Inventory of 1985 (IFN 1985 ) and the Tuscany Forest Inventory of 1998 (IFT 1998). The former was carried out during the period 1983-1987 according to a two-phase sampling, with the first phase aimed at discriminating forest/non-forest classes and at identifying forest species. ${ }^{29}$ During the second phase, sample plots were identified and trees measured to assess the main forest attributes (number of trees, basal area, standing volume, etc.); CAIs were measured only for productive forests and their figures are provided at national level.

The Tuscany Forest Inventory was carried out from 1990 to 1998 according to a two-phase sampling design. ${ }^{9}$ The first phase was aimed at classifying and identifying the different forest classes and at computing their extent. During the second phase, ground data were collected to characterize more than 5000 forest plots. Unlike the other two inventories, IFT published all information in a geo-referenced format, i.e. all measured quantities are provided for each sampling plot along with the topographic plot coordinates.

Finally, normalized difference vegetation index (NDVI) images taken by the Spot-Vegetation (VGT) sensor are derived from the archive of VITO (http://free.vgt.vito.be), which freely distributes pre-processed ten-day maximum value composite (MVC) images for the entire globe since April, 1998. The applied pre-processing steps comprise the radiometric calibration of the original channels and their geometric and atmospheric corrections. ${ }^{30}$ The final product of these steps are ten-day NDVI MVC images having a pixel size of about $1 \mathrm{~km}^{2}$. All ten-day images of Europe were downloaded for the period January 1999December 2008. From these images a window over Italy was selected for further processing.

\section{Modeling strategy \\ Estimation of GPP by C-Fix}

C-Fix is a Monteith type parametric model ${ }^{12,13}$ driven by temperature, radiation and the fraction of absorbed photosynthetically active radiation (fAPAR), quantified through its generalized relationship with NDVI. ${ }^{31}$ C-Fix combines satellitederived fAPAR with field based estimates of incoming solar radiation and air temperature, which are jointly used to simulate total photosynthesis. C-Fix is therefore conceptually simple and generally applicable, and can use inputs averaged over different time periods (most commonly ten-day to monthly). In particular, the annual GPP $\left(\mathrm{g} \mathrm{C} \mathrm{m}^{-2}\right.$ year $\left.^{-1}\right)$ of a forest can be computed as:

$$
G P P=\varepsilon \sum_{i=1}^{12} T_{\text {cori }} f A P A R_{i} \text { Rad }_{i}
$$

where $\varepsilon$ is the radiation use efficiency, $\mathrm{T}_{\text {cori }}$ is a factor accounting for the dependence of photosynthesis on air temperature $T_{i}$, fAPAR $R_{i}$ is the fraction of absorbed PAR, and $\operatorname{Rad}_{i}$ is the solar incident PAR, all referred to month i. fAPAR can be derived from the top of canopy NDVI according to the linear equation proposed by Myneni and Williams. ${ }^{31}$

The original C-Fix does not include a specific index which accounts for the possible short-term effect of water stress on photosynthesis, as is done by other Monteith type models (e.g. ref. 32 and 33). Maselli et al.,$^{14}$ therefore, introduced an

Table 1 Definition and main features of the six FTs considered and corresponding CORINE cover classes. The main features of the FTs were derived from INFC

\begin{tabular}{lllll}
\hline FT & Dominant forest species & CORINE class index/definition & Average standing volume $\left(\mathrm{m}^{3} \mathrm{ha}^{-1}\right)$ & ${\text { Average CAI }\left(\mathrm{m}^{3} \mathrm{ha}^{-1} \mathrm{year}^{-1}\right)}$ \\
\hline 1 & Evergreen oak & 7 -Holm oak & 74 & 2.3 \\
2 & Deciduous oak & 8 - Mediterranean broadleaves & 87 & 2.6 \\
3 & Chestnut & 2-Chestnut & 177 & 6.3 \\
4 & Beech & $4-$ Beech & 232 & 5.4 \\
5 & Plain/hilly conifers & 10 - Mediterranean pines & 134 & 3.7 \\
6 & Mountain conifers & $1-$ White fir/Norway spruce & 472 & 8.3 \\
\hline
\end{tabular}


additional water stress index to optimize the model application in Mediterranean environments, that are characterized by a long summer dry season during which vegetation growth is constrained by water availability. ${ }^{34}$ This modification is completed by the use of the MODIS temperature correction factors and radiation use efficiency ${ }^{35}$ in place of the original coefficients proposed by Veroustraete et al. ${ }^{12}$ A justification of all these choices is provided in Chiesi et al. ${ }^{36}$

Modified C-Fix was applied to simulate monthly GPP values of all Italian forests for the past decade (1999-2008) following the multi-step methodology described in Maselli et al. ${ }^{14}$ In summary, a $1 \mathrm{~km}^{2}$ dataset of monthly minimum and maximum temperatures, precipitation and solar radiation was derived from the available meteorological maps. These were further processed to compute maps of the temperature and water stress correction factors which are needed to drive Modified C-Fix. The SpotVGT ten-day NDVI images of the ten study years were corrected for residual disturbances, composed over monthly periods and processed to obtain fAPAR maps. All these maps were used to apply Modified C-Fix and yield monthly GPP images over the study years. These images were aggregated to compute an annual average GPP image of Italy, from which mean values were extracted for all forest types and Italian Regions.

\section{Estimation and evaluation of regional NPP}

The strategy proposed by Maselli et al., ${ }^{15}$ to address the mentioned uncoupling between ecosystem GPP and woody NPP is based on the integration of the outputs of C-Fix with those of a bio-geochemical model, BIOME-BGC. BIOME-BGC was developed at the University of Montana to estimate the storage and fluxes of carbon, nitrogen and water within terrestrial ecosystems. ${ }^{37}$ It requires daily weather data, general information on the environment (i.e. soil, vegetation and site conditions) and on parameters describing the ecophysiological characteristics of vegetation. The model is capable of finding a quasi-climax equilibrium with local eco-climatic conditions through the spinup phase and then computes all respirations and allocation processes. $^{38}$

The modeling of the quasi-climax condition has important consequences on the simulated carbon budget. The sum of all simulated respirations, in fact, becomes nearly equivalent to GPP, which makes annual NPP approach heterotrophic respiration (Rhet) and net ecosystem exchange (NEE) tend to zero. Also, such modeling makes the obtained GPP estimates similar to those produced by C-Fix, which are descriptive of all ecosystem components. ${ }^{14}$

The version of the model currently used includes complete parameter settings for six main biome types. ${ }^{38}$ These settings have been recently modified to adapt to Mediterranean ecosystems, which show eco-climatic features markedly different from those for which the model was originally developed. In particular, Tuscany forests were grouped into six ecosystem types, for which BIOME-BGC was calibrated by the use of GPP estimates derived from C-Fix. ${ }^{27}$ The six ecosystem types roughly correspond to the six forest types previously described, and a complete equivalence is assumed for the current objectives (see Table 1).

The application of BIOME-BGC in the Italian context requires the transformation of the quasi-climax respiration and allocation estimates into estimates of real forest ecosystems, which are generally far from climax due to the disturbances occurring. The modeling strategy of Maselli et al. ${ }^{15}$ considers the ratio between actual and potential forest standing volume as an indicator of ecosystem proximity to climax. This ratio can therefore be used to correct the photosynthesis and respiration estimates obtained by the model simulations. Accordingly, actual forest NPP $\left(\mathrm{NPP}_{\mathrm{A}}, \mathrm{g} \mathrm{C} \mathrm{m}^{-2}\right.$ year $\left.^{-1}\right)$, can be approximated as:

$$
N P P_{A}=G P P \times F C_{A}-R g r \times F C_{A}-R m n \times N V_{A}
$$

where GPP, Rgr and Rmn correspond to the GPP, growth and maintenance respirations estimated by BIOME-BGC $\left(\mathrm{g} \mathrm{C} \mathrm{m}^{-2}\right.$ year ${ }^{-1}$ ), and the two terms $\mathrm{FC}_{\mathrm{A}}$ (actual forest cover) and $\mathrm{NV}_{\mathrm{A}}$ (actual normalized standing volume), both dimensionless, are derived from the ratio between actual and potential tree volume. ${ }^{15}$

A schematic representation of the dependence of $\mathrm{NPP}_{\mathrm{A}}$ on $\mathrm{NV}_{\mathrm{A}}$ is shown in Fig. 2. The lower curve shows the absolute variation of $\mathrm{NPP}_{\mathrm{A}}$ relative to the potential (climax) ecosystem GPP simulated by BIOME-BGC: $\mathrm{NPP}_{\mathrm{A}}$ starts from 0 , when no tree is present, reaches a maximum at about $30-40 \%$ of the potential (climax) volume, and shows a subsequent slight decrement when the forest approaches full maturity. The upper curve indicates the same variation relative to the GPP of the tree ecosystem compartment, i.e. the GPP which can be attributed only to tree canopies $\left(\mathrm{GPP}_{\mathrm{A}}\right)$. The ratio $\mathrm{NPP}_{\mathrm{A}} / \mathrm{GPP}_{\mathrm{A}}$ shows only a marginal decrease while approaching maturity, which is related to forest ageing. A more detailed explanation of this scheme is reported in Maselli et al., ${ }^{15}$ together with all assumptions and approximations for its application.

Due to the previously described functional equivalence of $\mathrm{C}$ Fix and BIOME-BGC GPP estimates, the outputs of the two

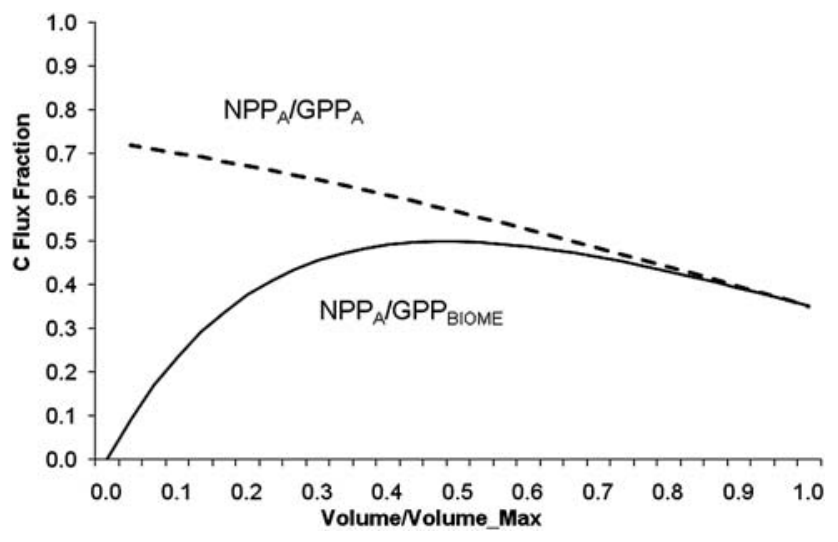

Fig. 2 Scheme of the dependence of actual tree $\mathrm{NPP}\left(\mathrm{NPP}_{\mathrm{A}}\right)$ on normalized forest volume $\left(\mathrm{NV}_{\mathrm{A}}\right)$. $\mathrm{NPP}_{\mathrm{A}}$ is expressed both relative to the ecosystem GPP (as simulated by BIOME-BGC or C-Fix) and to the actual GPP of the tree compartment $\left(\mathrm{GPP}_{\mathrm{A}}\right)$. The two curves converge when $\mathrm{NV}_{\mathrm{A}}=1$, i.e. when actual standing volume approaches the potential maximum and the GPP of the tree compartment equals that of the ecosystem. The shape of the two curves can vary depending on the photosynthesis, respiration and allocation patterns simulated by BIOME-BGC. The scheme is derived from Maselli et al.,${ }^{15}$ who provide a more complete explanation. 
models can be integrated by multiplying BIOME-BGC photosynthesis and respiration estimates for a ratio between C-Fix and BIOME-BGC GPP. In the present case, however, BIOME-BGC could be applied only to the Tuscany territory, due to the lack of daily meteorological data for the rest of Italy. This required the application of an approximation methodology based on the use of two further assumptions. First, all respirations simulated by BIOME-BGC were assumed to vary linearly following photosynthesis, which allowed the calculation of growth and maintenance respirations as constant fractions of GPP for each forest type. Second, a similar assumption was applied to simulate spatial variations of maximum standing volume and leaf area index (LAI), which were needed to compute $\mathrm{FC}_{\mathrm{A}}$ and $\mathrm{NV}_{\mathrm{A} \cdot{ }^{15}}$ Both these assumptions are in reasonable accordance with BIOME-BGC logic, which simulates ecosystems whose all main properties and functions are descriptive of a quasi-climax equilibrium.

The reference values of GPP, respirations, stem carbon and LAI were recovered for each forest type from a BIOME-BGC simulation performed in Tuscany over a 12 -year time period. ${ }^{36}$ Stem carbon was converted into maximum standing volume using the coefficients given by Federici et $a .^{8}$ A further coefficient, unique for all six forest types (0.624), was applied to correct the obtained maximum volume values, which are significantly overestimated with respect to those measured in Tuscany forests. ${ }^{15}$ BIOME-BGC estimates were then rescaled for each forest type following relevant Modified C-Fix GPP outputs. The regional values of actual forest standing volume needed to compute $\mathrm{FC}_{\mathrm{A}}$ and $\mathrm{NV}_{\mathrm{A}}$ were taken for each forest type and Region from INFC statistics. All these data were combined within eqn (2) to compute $\mathrm{NPP}_{\mathrm{A}}$ for each forest type and Region. The BIOME-BGC allocation factors of the six forest types were used to convert the regional values of $\mathrm{NPP}_{\mathrm{A}}$ into accumulated stem carbon (C) estimates, which were transformed into CAIs through the basic wood densities of Federici et $a .^{8}$

Specifically, CAI values $\left(\mathrm{m}^{3} \mathrm{ha}^{-1}\right.$ year $\left.{ }^{-1}\right)$ were computed through the formula:

$$
C A I=N P P_{A} \times S C A / B E F / B W D \times 2 \times 100
$$

where SCA is the Stem C Allocation ratio, BEF the volume of above ground biomass/standing volume Biomass Expansion Factor (both dimensionless), and BWD is the Basic Wood Density $\left(\mathrm{Mg} \mathrm{m}^{-3}\right)$. The SCAs of the six forest types are those of BIOME-BGC, while BEFs and BWDs are taken again from Federici et al. ${ }^{8}$ (Table 2). The multiplication by 2 accounts for the transformation from carbon to dry matter, and that by 100 for the change in magnitude from $\mathrm{g} \mathrm{m}^{-2}$ to $\mathrm{Mg} \mathrm{ha}^{-1}$.

The CAI modeled values were finally validated through comparison with the INFC CAIs considering only the Regions where the presence of each forest type was significant (at least $101-\mathrm{km}^{2}$ pixels). The comparisons were first carried out separately for each forest type, summarizing the results by the coefficient of determination $\left(\mathrm{r}^{2}\right)$, the root mean square error (RMSE) and the percentage mean bias error $(\mathrm{MBE} \%$, i.e. $\mathrm{MBE} /$ measured average $\times 100)$. The same comparison was finally repeated considering all six forest types contemporaneously.

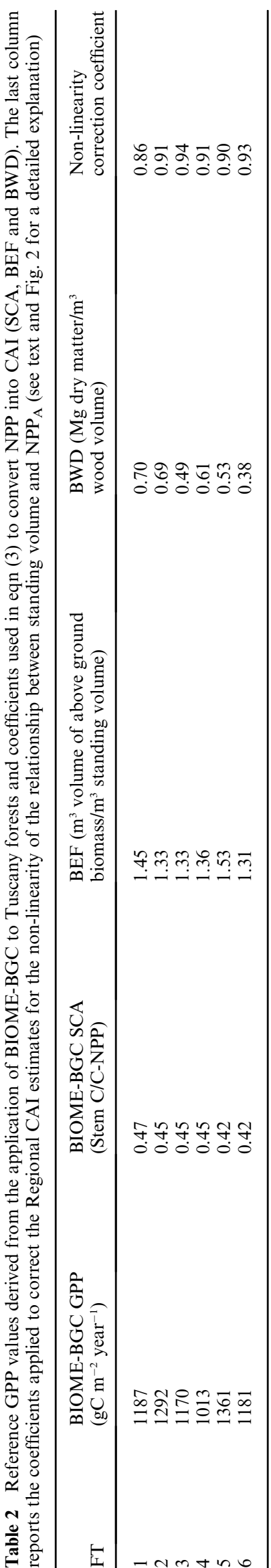

1086 | J. Environ. Monit., 2010, 12, 1082-1091 


\section{Results}

An image descriptive of mean annual forest GPP over the study period is shown in Fig. 3. GPP mostly ranges from 700 to $1800 \mathrm{~g}$ $\mathrm{C} \mathrm{m}^{-2}$ year $^{-1}$, and is similar to the GPP values simulated by BIOME-BGC for Tuscany forests (Table 2). In general, Mediterranean forest types (FT 1, among broadleaf and FT 5, among needleaf) show the highest GPP levels. These forests grow in temperate areas, and their photosynthetic activity is limited mainly by water availability during the dry season. Mountain

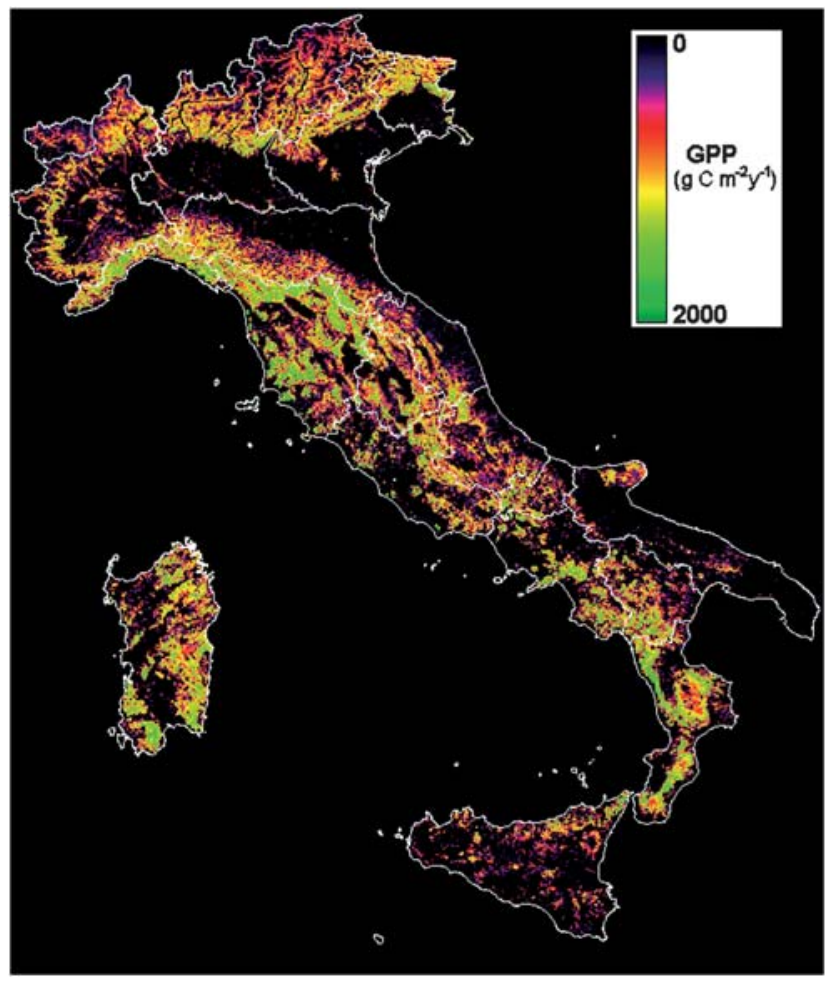

Fig. 3 Image of mean annual forest GPP computed by the modeling approach over the period (1999-2008), with superimposed administrative boundaries of the 20 Italian Regions.

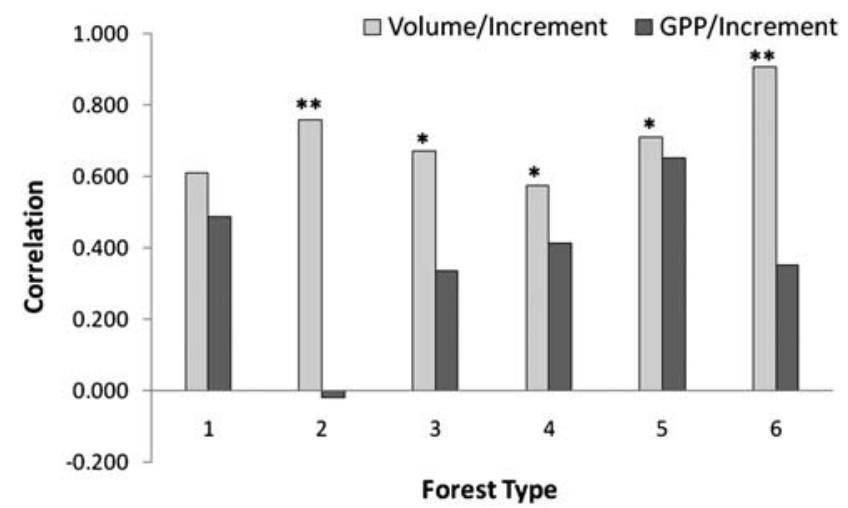

Fig. 4 Correlations of the regional INFC CAI values with relevant values of standing volume (A) and with regional C-Fix GPP estimates (B); the correlations are provided for the six forest types considered $\left(^{*}=\right.$ significant correlation, $\mathrm{P}<0.05 ; * *=$ highly significant correlation, $\mathrm{P}<$ 0.01 ). ecosystems (FT 4 and FT 6), which are limited by the thermal factor during most of the year, show the lowest GPP levels. Overall, the prevalence of thermal limitation determines decreasing trends of GPP from southern, plain areas to northern mountain zones, following the main latitudinal and altitudinal gradients. These trends are complicated by the previously mentioned occurrence of summer water stress in the most arid areas of Central-Southern Italy.

Fig. 4 summarizes the results of correlation analyses performed to assess the dependence of regional INFC increments on standing volumes and C-Fix GPP estimates. The correlation coefficients are computed for each forest type considering all values of the three variables which correspond to the 20 Italian Regions. The absence or marginal presence of some forest types in some Regions, however, reduce the number of points considered in each case (from 9 to 17, see Fig. 5). CAI shows high positive correlations with standing volume $(0.6<\mathrm{r}<0.9)$, and is less correlated with GPP $(0.0<\mathrm{r}<0.6)$. The correlations between standing volume and GPP, not shown, are partly negative $(-0.3<\mathrm{r}<0.5)$ and all lower than those between CAI and GPP.

The comparisons between measured (INFC) and modeled CAI values yield the results shown in Fig. 5A-F. In general, the moderate to high correlations found $\left(\mathrm{r}^{2}\right.$ from 0.327 for FT 1 to 0.620 for FT 5) are indicative of the relatively good agreement between the two data series. The modeling approach, however, overestimates CAI in almost all cases. The overestimation ranges from $7 \%$ for FT 3 and FT 6 to almost $80 \%$ for FT 1 . In this last case, the national INFC average CAI of $2.4 \mathrm{~m}^{3} \mathrm{ha}^{-1}$ is notably lower than the modeled average of $4.4 \mathrm{~m}^{3} \mathrm{ha}^{-1}$.

Fig. 6 reports the comparison between INFC and modeled increments of all forest types (69 data points). The accordance between the two data series is high $\left(\mathrm{r}^{2}=0.723, \mathrm{P}<0.01\right)$, but the modeled CAIs are on average 19\% higher than the CAIs from INFC.

\section{Discussion}

The current application of Modified C-Fix on a national scale relies on the consolidated capacity of the model to correctly predict the annual GPP of Mediterranean forests at $1 \mathrm{~km}^{2}$ spatial resolution. ${ }^{15}$ As previously noted, however, this capacity is not sufficient to guarantee the correct estimation of Italian forest NPP, due to the complexity of the relationships which link total ecosystem production to woody biomass accumulation. This expectation is confirmed by the comparison of INFC data with the model outputs, which shows that GPP is mostly uncoupled with woody NPP. Specifically, the correlations reported in Fig. 4 indicate that, on large Italian territories, CAI is only weakly related to GPP. In contrast, CAI is mainly driven by standing volume, which is almost independent of GPP.

This behavior can be reasonably interpreted considering that forest GPP includes the photosynthesis of all non-tree ecosystem components (grasses and shrubs), which can be relevant in disturbed environments but only marginally contributes to woody biomass accumulation. As a consequence, actual standing volume is mostly determined by forest disturbance history and influences CAI more effectively than potential site production (see scheme of Fig. 2). Such an interpretation is in accordance with existing documentation, which testifies to the strong 


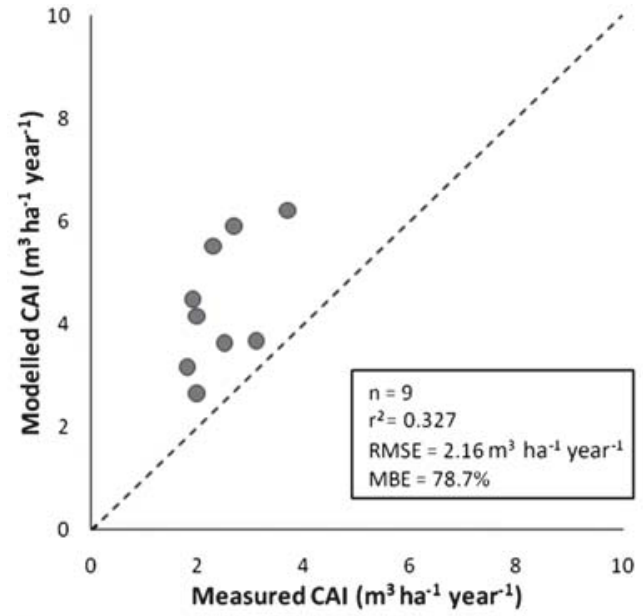

A

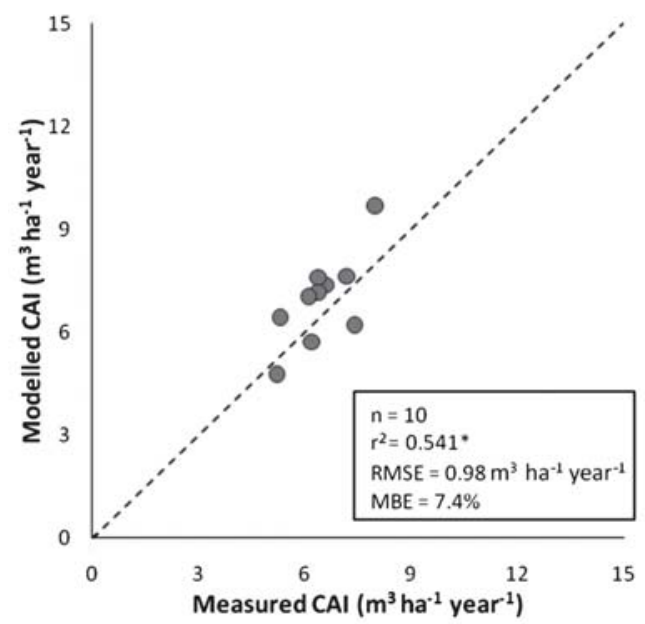

C

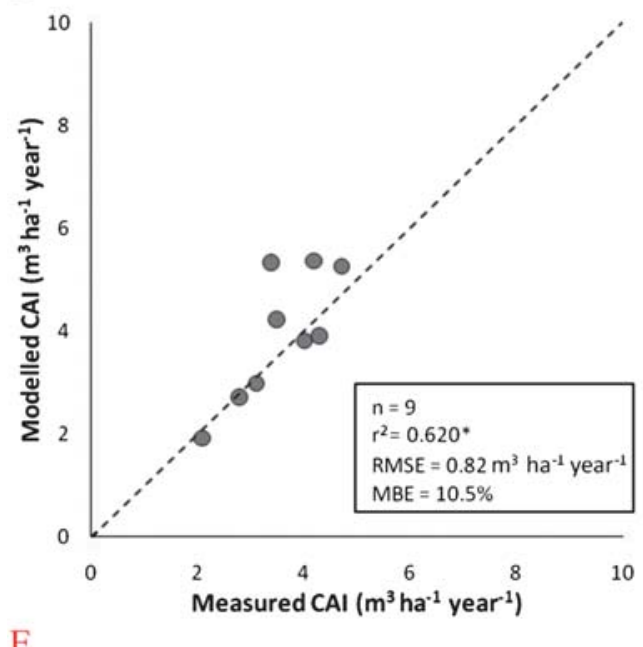

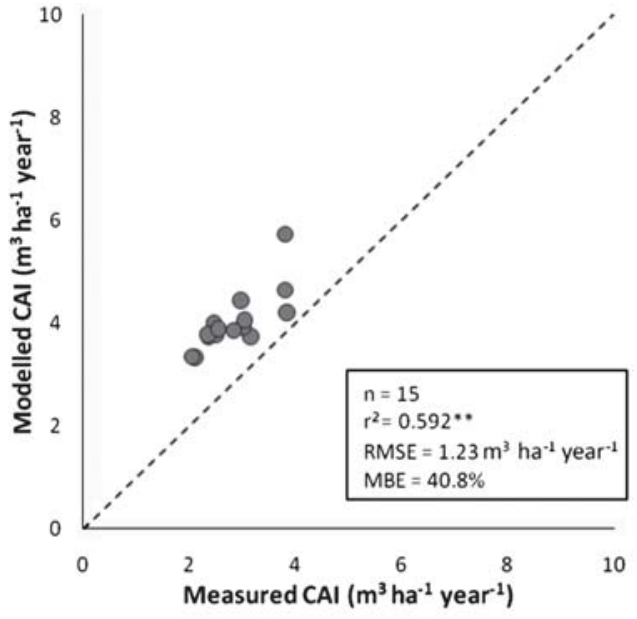

B

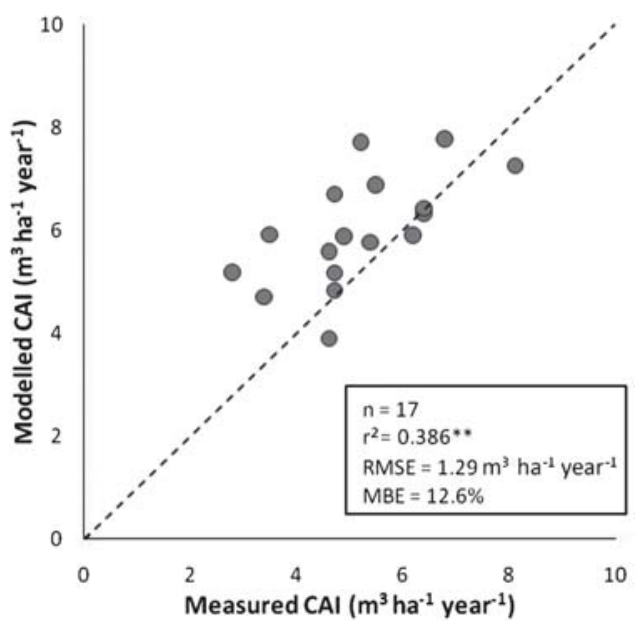

$\mathrm{D}$

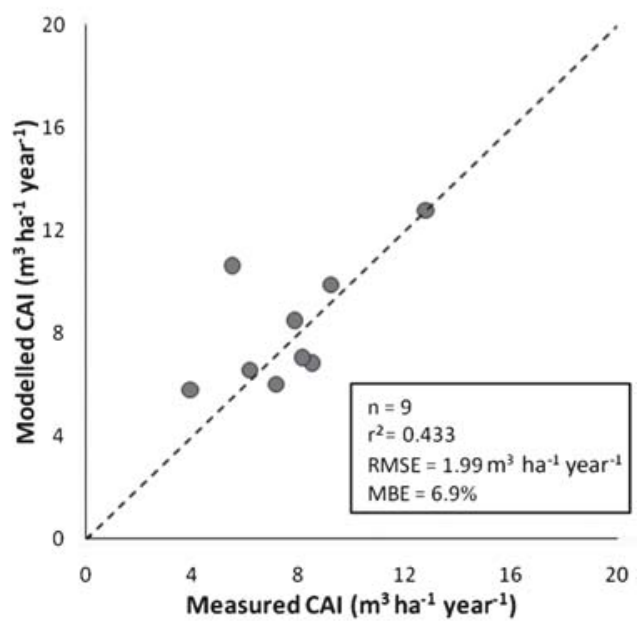

$\mathrm{F}$

Fig. 5 A-F Comparisons between the regional values of CAI provided by INFC and those estimated by the modeling strategy for each forest type considered $\left(^{*}=\right.$ significant correlation, $\mathrm{P}<0.05 ; * *$ highly significant correlation, $\left.\mathrm{P}<0.01\right)$.

pressure directly or indirectly exerted by human activities on Italian forest resources during the last centuries. ${ }^{39}$

This situation prevents the application of simple estimation methods which consider NPP as a constant ratio of GPP. ${ }^{40}$ In the current case, the constant ratio approach provides increment estimates which are almost two times higher than those from INFC (data not shown). A similar overestimation is obtained when directly using the NPP/GPP fractions simulated by 


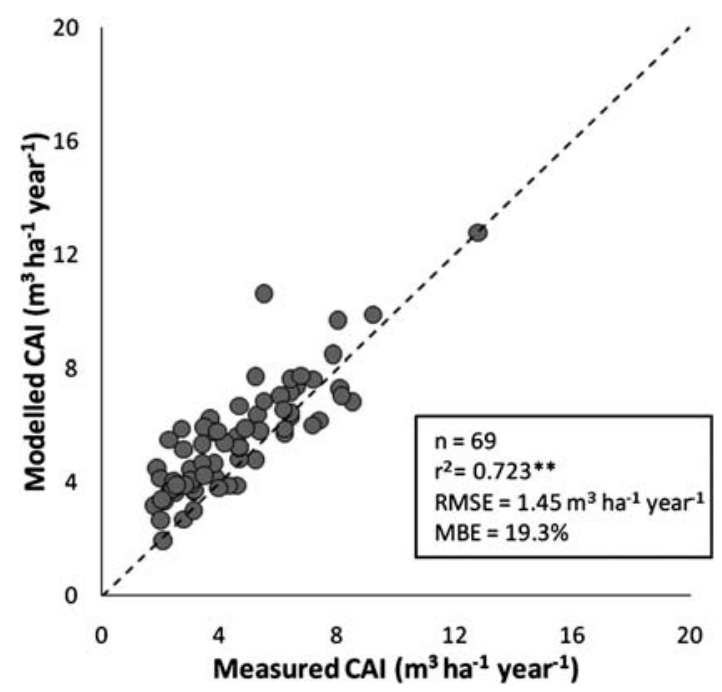

Fig. 6 Comparison between the regional values of CAI provided by INFC and those estimated by the modeling strategy for all forest types considered $(* *=$ highly significant correlation, $\mathrm{P}<0.01)$

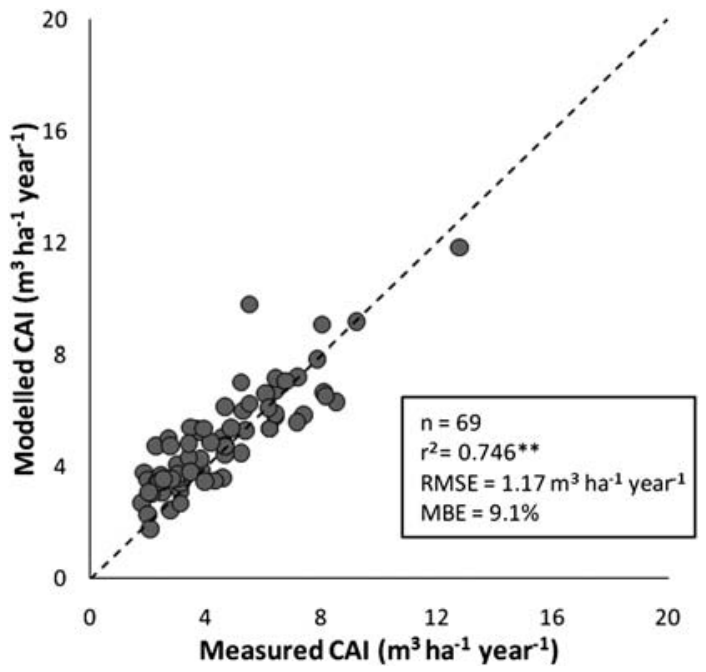

Fig. 7 Comparison between the regional values of CAI provided by INFC and those estimated by the modeling strategy and reduced through the application of the non-linearity correction coefficients of Table 2 for all forest types considered $(* *=$ highly significant correlation, $\mathrm{P}<0.01$ ).
BIOME-BGC, which are still descriptive of forest ecosystems at equilibrium conditions.

The modeling strategy of Maselli et al. ${ }^{15}$ was specifically developed to account for the effects of intense forest disturbances. The current application of this strategy yields regional CAI estimates which are globally in good accordance with the INFC measurements, but are 19\% higher than these. Part of this discrepancy is attributable to the intrinsic and mostly unavoidable inaccuracy of the modeling approach applied and of the data layers used. As regards the former factor, a major error source can be ascribed to the tendency of BIOME-BGC to overestimate the maximum stem carbon values needed for the computation of $\mathrm{FC}_{\mathrm{A}}$ and $\mathrm{NV}_{\mathrm{A}} \cdot{ }^{41,15}$ This problem was currently corrected by the application of a unique empirical coefficient for all forest types, which is, however, a suboptimal solution. The sensitivity of the modeling strategy to the possible presence of errors in the input data layers has been recently investigated by Chiesi et al. ${ }^{36}$ The results obtained indicate that the integration of C-Fix and BIOME-BGC outputs notably reduces the negative effects of inaccurate ground data thanks to the information provided by NDVI-derived fAPAR estimates.

In addition to these error sources, the discrepancy found can be attributed to the use of BIOME-BGC outputs descriptive only of one Italian Region (Tuscany). Such a use, in fact, can not fully reproduce the variability in forest conditions which would be simulated by complete BIOME-BGC runs performed over the entire national territory. Indeed, this problem is minimized by the fact that, thanks to its geographical position, orography and extent, Tuscany is the Italian Region which shows the greatest variety of forest types and conditions.

An in-depth analysis of the results reveals that the tendency to CAI overestimation is partly due to the current implementation of the modeling approach. This tendency derives from the use of standing volume data aggregated per Region for the computation of $\mathrm{FC}_{\mathrm{A}}$ and $\mathrm{NV}_{\mathrm{A}}$, which directly affects the estimation of $\mathrm{NPP}_{\mathrm{A}}$. The concavity of the relationship between $\mathrm{NV}_{\mathrm{A}}$ and $\mathrm{NPP}_{\mathrm{A}}$, in fact, determines a significant overestimation of the latter when the modeling approach is fed with standing volume averages in place of the original, dispersed data (see Fig. 2). An analysis of the available IFT data quantifies this overestimation in a range from 6 to 14\% (Table 2). Per-class coefficients ranging from 0.86 to 0.94 can therefore be applied to correct the simulated $\mathrm{NPP}_{\mathrm{A}}$ and, consequently, CAI values. Fig. 7 shows that the accordance of the corrected CAI estimates with the INFC measurements is improved with respect to Fig. $6\left(r^{2}\right.$ from 0.723 to 0.746), while both RMSE and MBE are notably reduced. More

Table 3 Mean values of standing volume (VOL) and CAI for the six forest types considered, drawn from INFC 2008 and IFT 1998 for Tuscany; CAI is provided in real and relative (Rel_CAI) values

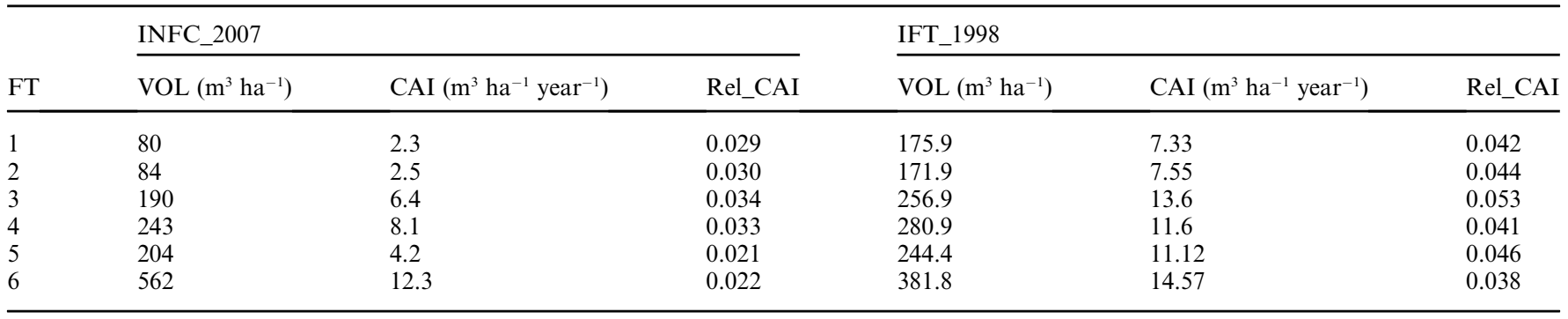


specifically, the correction significantly reduces the previous model overestimation of the INFC measurements, which becomes lower than $10 \%$.

This relatively small overestimation is partly in contrast with the results of a previous investigation conducted in Tuscany by Maselli et al., ${ }^{15}$ which indicated that the applied approach is capable of producing nearly unbiased estimates not only of GPP and NEE, but also of NPP. The CAI estimates obtained in that case, which were referred only to dense forest plots, were slightly higher than the current ones but correctly reproduced the relevant measurements of the Tuscany forest inventory (IFT 1998). This implies that the increment statistics of IFT are consistently higher than those of INFC. The existence of this discrepancy is confirmed by the examination of Table 3, which compares standing volume and CAI statistics derived from the two inventories for the six forest types. All relative increments from IFT are significantly higher than those from INFC.

A similar pattern is found when considering the data derived from the previous Italian Forest Inventory (IFNI 1985), for which only broadly aggregated statistics are available. This inventory reported relative increments of high forests equal to $3.7 \%$, versus a similar value of $2.8 \%$ from INFC. This corresponds to a decrement of about $25 \%$, which is likely too high to be attributed to random factors and/or to the time lag which occurred between the two inventories (about 20 years).

In contrast, the increment statistics of INFC are in line with those of the Inventory of Forest Carbon Stocks (InFoCarb), which has been recently carried out in the Province of Trento (Central-Eastern Alps) and whose results are summarized by Tabacchi and Gasparini. ${ }^{42}$ These authors report an annual provincial total of relative carbon increment equal to $1.83 \%$, which is nearly coincident with an INFC increment of $1.96 \%$ as well as with our modeled increment of $1.88 \%$ for that Province.

All these observations confirm the existence of the problematic framework mentioned in the introductory section. As a matter of fact, the disagreements among the various inventories as well as the slight overestimation of our modeling approach with respect to INFC data could be originated by a number of causes. Among these, a major one could be related to the use of different definitions of forest area and forest classes. ${ }^{43}$ This is a well known source of uncertainty in the collection of forest statistics, since categorical definitions are generally variable depending on the context and objectives of the inventory. ${ }^{44}$

Additional uncertainty may derive from the procedures applied for the estimation of CAI. Actually, not all plots where conventional forest attributes are measured (number of trees, basal area, standing volume, etc.) are surveyed to derive increment statistics, due to the complexity which is inherent in the collection and analysis of tree cores. For the same reason, cores are taken only from a limited number of trees within the selected plots. The procedures which are used to select cored plots and trees are generally different within various inventories, which may give rise to a certain variability in the relationships between measured standing volume and CAI.

Other possible causes of the discrepancies found among the results of the considered forest inventories could be due to the application of different data elaboration protocols. This can concern the methods applied and the coefficients used to compute standing volume and CAI from the basic variables that are measured within each plot (stem diameter, stem height, stem diameter increment, etc.). Indeed, the need for harmonizing forest inventory protocols is a current topical issue. ${ }^{45}$

\section{Conclusions}

The modeling strategy applied was specifically developed to account for the state of Italian forests, which are kept far from equilibrium conditions by a long and intense disturbance history. The application of this strategy requires, in addition to the data needed to feed the two basic models (C-Fix and BIOME-BGC), spatially extended estimates of forest standing volume, which can be obtained by both conventional and remote sensing methods. ${ }^{46}$ Previous tests of the strategy have confirmed its potential to predict net forest carbon fluxes, at least at a scale which is suitable to produce regional statistics.

The application of this strategy has yielded a significant overestimation of the forest CAI statistics derived from INFC (about 19\%). Part of this overestimation is due to the current implementation of the modeling approach, which can be properly corrected. The corrected increment estimates are in good accordance with INFC statistics and show only a marginal residual tendency to overestimation (about 9\%). In general, such a discrepancy can be considered satisfactory bearing in mind all the possible sources of uncertainty which characterize the modeling approach. This is particularly the case considering that also the reference CAI measurements are affected by intrinsic uncertainty, whose relevance is demonstrated by the incomplete agreement among the results of different inventories.

In summary, the analyses performed confirm the critical nature of this subject area. All methodologies capable of providing regional estimates of forest NPP and CAI are affected by numerous sources of uncertainty. From a practical viewpoint, this can have important consequences on the regional scale assessment of carbon accumulation in forest ecosystems. The use of estimation methods based on the integration of multisource ground and remote sensing data is proposed as a possible means to explore and, if possible, reduce such uncertainty with limited labor and cost expenses additional to those of the ground data collection and elaboration.

\section{Appendix 1-List of acronyms and abbreviations}

$\begin{array}{ll}\text { BEF } & \text { Biomass Expansion Factor } \\ \text { BWD } & \text { Basic Wood Density } \\ \text { C } & \text { Carbon } \\ \text { CAI } & \text { Current Annual Increment } \\ \text { fAPAR } & \text { Fraction of Absorbed Photosynthetically } \\ & \text { Active Radiation } \\ \text { FC } & \text { Actual Forest Cover } \\ \text { FT } & \text { Forest Type } \\ \text { GPP } & \text { Gross Primary Production } \\ \text { IFT } & \text { Inventario Forestale Toscano (Tuscany Forest } \\ & \text { Inventory) } \\ \text { INFC } & \text { Inventario Nazionale delle Foreste e dei } \\ & \text { serbatoi forestali di Carbonio (National } \\ & \text { Inventory of Forests and forest Carbon sinks) } \\ \text { LAI } & \text { Leaf Area Index }\end{array}$


NDVI

NPP

$\mathrm{NPP}_{\mathrm{A}}$

$\mathrm{NV}_{\mathrm{A}}$

SCA

Normalized Difference Vegetation Index

Net Primary Production

Actual Forest NPP

Actual Normalized Standing Volume

Stem C Allocation ratio

\section{Acknowledgements}

The work was partially carried out under the CarboItaly project, funded by the FISR program of the Italian Ministry of University and Research. The authors wish to thank F. Veroustraete and S.W. Running for their precious suggestions on the application of C-Fix and BIOME-BGC, respectively. Thanks are also due to two anonymous JEM referees for their helpful comments on the original manuscript.

\section{References}

1 FAO, Global Forest Resource Assessment, Progress towards sustainable forest management, 2005, available on the web page http://www.fao.org/docrep/008/a0400e/a0400e00.htm (last accessed June 10th 2009).

2 F. Hagedorn, S. Maurer, P. Egli, P. Blaser, J. B. Bucher and R. Siegwolf, Eur. J. Soil Sci., 2001, 52, 619-628.

3 R. H. Waring and S. W. Running, Forest Ecosystems, Analysis at Multiples Scales, 2nd edn, Academic Press, San Diego, USA, 1998, pp. 55.

4 P. Corona and M. Marchetti, Plant Biosys., 2007, 141, 243-251.

5 P. Gasparini, F. De Natale, L. Di Cosmo, C. Gagliano, I. Salvadori, G. Tabacchi and V. Tosi, MiPAAF, Ispettorato Generale Corpo Forestale dello Stato, CRA-MPF, Trento, Italy, 2007.

6 P. Gasparini, R. Bertani, F. De Natale, L. Di Cosmo and E. Pompei, J. Environ. Monit., 2009, 11, 761-768.

7 F. Evrendilek, J. Environ. Monit., 2004, 6, 26-30.

8 S. Federici, M. Vitullo, S. Tulipano, R. De Lauretis and G. Seufert, iForest - Biogeosciences and Forestry, 2008, 1, 86-95.

9 P. V. Arrigoni, M. Raffaelli, M. Rizzotto, F. Selvi, D. Viciani, L. Lombardi, B. Foggi, C. Melillo, R. Benesperi, G. Ferretti, S. Benucci, S. Turrini, P. L. di Tommaso, M. Signorini, E. Bargelli, U. Miniati, C. Farioli, V. de Dominicis, S. Casini, A. Chiarucci, P. E. Tomei, M. Ansaldi, S. Maccioni, E. Guazzi, L. Zocco Pisana, A. Cenerini, L. Dell'Olmo and E. Menicagli, La vegetazione forestale. Serie Boschi e Macchie di Toscana. Regione Toscana, Giunta regionale, 1998, $215 \mathrm{pp}$.

10 G. Chirici, A. Barbati and F. Maselli, Forest Ecol. Manage., 2007, 246, 285-295.

11 F. Maselli, A. Barbati, M. Chiesi, G. Chirici and P. Corona, Remote Sens. Environ., 2006, 100, 563-575.

12 F. Veroustraete, H. Sabbe, D. P. Rasse and L. Bertels, Int. J. Remote Sens., 2004, 25, 769-792.

13 F. Veroustraete, H. Sabbe and H. Eerens, Remote Sens. Environ., 2002, 83, 376-399.

14 F. Maselli, D. Papale, N. Puletti, G. Chirici and P. Corona, Remote Sens. Environ., 2009, 113, 657-667.

15 F. Maselli, M. Chiesi, M. Moriondo, L. Fibbi, M. Bindi and S. W. Running, Ecol. Modell., 2009, 220, 330-342.

16 S. T. Gower, R. E. McMurtri and D. Murty, Tree, 1996, 11, 378-382.

17 C. Song and C. E. Woodcock, Ecol. Modell., 2003, 164, 33-47.

18 P. E. Thornton, B. E. Law, H. L. Gholz, K. L .Clark, E. Falge, D. S. Ellsworth, A. H. Goldstein, R. K. Monson, D. Hollinger,

M. Falk, J. Chen and J. P. Sparks, Agric. Forest Meteorol., 2002, 113, 185-222.

19 S. Van Tuyl, B. E. Law, D. P. Turner and A. I. Gitelman, Forest Ecol. Manage., 2005, 209, 273-291.

20 R. Petritsch, H. Hasenauer and S. A. Pietsch, Forest Ecol. Manage., 2007, 242, 324-336.

21 O. Bergeron, H. A. Margolis, C. Coursolle and M. A. Giasson, Agric. For. Met., 2008, 148, 537-548.

22 C. P. Osborne, P. L. Mitchell, J. E. Sheehy and F. I. Woodward, Global Change Biol., 2000, 6, 445-458.

23 S. A. Pietsch, H. Hasenauer and P. E. Thornton, Forest Ecol. Manage., 2005, 211, 264-295.

24 E. P. Odum, 1953, Fundamentals of ecology, W. B. Saunders Company, Philadelphia.

25 C. Maricchiolo, V. Sambucini, A. Pugliese, C. Blasi, M. Marchetti, G. Chirici and P. Corona, Proceedings of the 8th National Conference ASITA "Geomatica: standardizzazione, interoperabilità e nuove tecnologie", Roma, Italy, 2004.

26 EEA, European Topic Center-Terrestrial Environment, Final version, Copenhagen, Denmark, 2002, p. 69.

27 M. Chiesi, F. Maselli, M. Moriondo, L. Fibbi, M. Bindi and S. W. Running, Ecol. Modell., 2007, 206, 179-190.

28 L. Fattorini, M. Marcheselli and C. Pisani, J. Agric. Biol. Environ. Stat., 2006, 11, 296-316.

29 ISAFA, 2009, http://www.isafa.it/scientifica/inventari/ifni_85.htm, last accessed November 12, 2009.

30 P. Maisongrande, B. Duchemin and G. Dedieu, Int. J. Remote Sens., 2004, 25, 9-14.

31 R. B. Myneni and D. L. Williams, Remote Sens. Environ., 1994, 49, 200-211.

32 C. B. Field, J. T. Randerson and C. M. Malmstrom, Remote Sens. Environ., 1995, 51, 74-88.

33 S. W. Running, R. R. Nemani, F. A. Heinsch, M. Zhao, M. Reeves and H. Hashimoto, BioScience, 2004, 54, 547-560.

34 Mediterranean Land-surface Processes Assessed from Space, ed. H. J. Bolle, M. Eckardt, D. Koslowsky, F. Maselli, J. Melia-Miralles, M. Menenti, F. S. Olesen, L. Petkov, I. Rasool and A. Van de Griend, Springer, Berlin, 2006, 760 pp.

35 F. A. Heinsch, M. Reeves, P. Votava, S. Kang, C. Milesi, M. Zhao, J. Glassy, W. M. Jolly, R. Loehman, C. F. Bowker, J. S. Kimball, R. R. Nemani and S. W. Running, User's Guide GPP and NPP (MOD17A2/A3) Products NASA MODIS Land Algorithm, Version 2.0, December 2, 2003. www.ntsg.umt.edu/modis/ (accessed on 12 November, 2009).

36 M. Chiesi, L. Fibbi, L. Genesio, B. Gioli, F. Maselli, R. Magno, M. Moriondo and F. Vaccari, Ecosystems, 2010, submitted.

37 S. W. Running and E. R. Hunt, in Scaling physiological processes: leaf to globe, ed. J. R. Ehleringer and C. B. Field, Academic Press, San Diego, USA, 1993, pp. 141-158.

38 M. A. White, P. E. Thornton, S. W. Running and R. R. Nemani, Earth Interact., 2000, 4, 1-85.

39 P. Corona, A. Macrì and M. Marchetti, L'Italia Forestale e Montana, 2004, 2, 119-136.

40 R. H. Waring, J. J. Landsberg and M. Williams, Tree Physiol., 1998, 18, 129-134.

41 S. A. Pietsch and H. Hasenauer, Global Change Biol., 2006, 12, 1658 1669.

42 G. Tabacchi and P. Gasparini, Forest@, 2008, 5, 195-200.

43 V. Tosi and M. Monteccone, Forest@, 2004, 1, 148-164.

44 C. Vidal, A. Lanz, E. Tomppo, K. Schadauer, T. Gschwantner, L. di Cosmo and N. Robert, Silva Fennica, 2008, 42, 247-266.

45 R. E. McRoberts, E. O. Tomppo, K. Schadauer, C. Vidal, G. Stahl, G. Chirici, A. Lanz, E. Cienciala, S. Winter and W. B. Smith, J. Forestry, 2009, 107, 179-187.

46 R. E. Mc Roberts and E. O. Tomppo, Remote Sens. Environ., 2007, 110, 412-419. 